\title{
Mechanism analysis and model calculation of chloride ion diffusion in reinforced concrete structure
}

\author{
Faqiang $\mathrm{Yu}^{1}$, Weiwei Gao ${ }^{1}$, Wenchao Liu ${ }^{1}$ \\ ${ }^{1}$ CCCC Fourth Highway Engineering CO., LTD., Beijing, 100022, China
}

\begin{abstract}
Chloride-induced corrosion of steel in reinforced concrete structures is one of the major causes of their deterioration over time. The analysis and research on the diffusion mechanism of chloride ions in reinforced concrete structures is still insufficient, and it is necessary to calculate the path of chloride ions based on theoretical models. In this paper, the fick's second law was used to describe the free chloride concentration evolution in concrete. The Monte Carlo simulation was used to predict the cumulative distribution of corrosion initiation of reinforcing steel. The results show that the calculated results of the established model are in good agreement with the measured results.
\end{abstract}

\section{Introduction}

Reinforced concrete (RC) structure was very commonly used due to its easy material resource, simplified preparation and low cost[1-4]. Corrosion of reinforcing steel due to chloride ingression had been a critical issue for the durability design and construction of RC structures in marine environments. The high alkalinity of the concrete pore solution provided a protection of reinforcing steel in concrete against corrosion by forming a thin oxide layer so called passivation film. When the concentration of chloride ion on the reinforcing steel surface reached a threshold value called critical concentration, depassivation of reinforcing steel initiated and corrosion started to occur [5-7] . Chloride ingressed into concrete involved several transport processes such as diffusion (i.e., the motion of chloride ion within the pore solution caused by the concentration gradient), convection (i.e., the motion of chloride ion together with the pore solution within the concrete caused by the moisture gradient), capillary absorption and migration[8-12]. In this paper, finite element model was established to calculate corrosion initiation time.

\section{The difference between 1-D diffusion and 2-D diffusion}

\subsection{Free chloride concentration evolution}

The evolution of free chlorine ion concentration at point $\mathrm{A}, \mathrm{B}$ and $\mathrm{C}$ with time were shown in Figure 1. As can be seen, the chloride ion reached point $\mathrm{B}$ and $\mathrm{C}$ in the first place due to closer distance compared to point A. And they were almost same in the first 50 years, because the free chlorine ion from left side had not yet diffuse to point B. When the free chlorine ion from left side reached point B, chlorine ion concentration at point $\mathrm{B}$ was gradually higher than point $\mathrm{C}$. The free chlorine ion concentration at point A was gradually higher than point $\mathrm{B}$ with time, because the influence of the two-dimensional diffusion is more significant for point $\mathrm{A}$. 


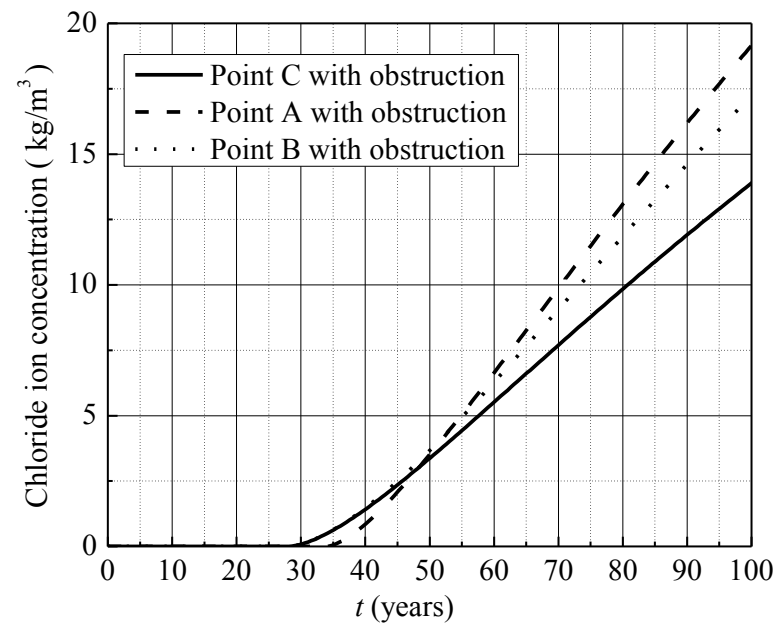

Figure. 1 Free chloride concentration evolution at point $\mathrm{A}$ and $\mathrm{B}$

Corrosion initiation time at point $\mathrm{A}, \mathrm{B}$ and $\mathrm{C}$ for different concrete cover and each bay were shown in Figure 6 and 7. As can be seen, corrosion initiated earlier at point $A$ than $B$ regardless of thickness of concrete cover, concrete strength and external environmental condition. Therefore taking point $\mathrm{A}$ to represent the reinforcing steel placed in corner square cross-section would conform to the real case better.

\subsection{Corrosion initiation time at point $A$ and $B$ for different concrete cover}

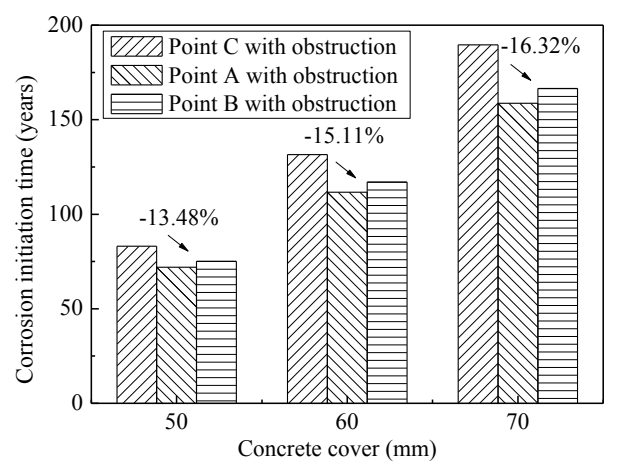

(a) $\mathrm{C} 50$
As shown in Figure 6, as the concrete cover from $50 \mathrm{~mm}$ to $70 \mathrm{~mm}$, the corrosion initiation time at point A was $13.48 \%$ to $16.32 \%$ smaller than point $\mathrm{C}$ for $\mathrm{C} 50$ concrete and $15.35 \%$ to $18.26 \%$ for C60 concrete. It was found that the thicker the thickness of the concrete cover was, the more remarkable the influence of 2-D diffusion was. And the influence was more remarkable for C60 concrete.

Figure. 2 Corrosion initiation time at point A and B for different concrete cover

As shown in Figure 7, from Haikou bay to Dalian bay, the corrosion initiation time at Poona A was $16.32 \%$ to $15.38 \%$ smaller for C50 concrete and $18.26 \%$ to $17.41 \%$ for $\mathrm{C} 60$ concrete. It was found that the higher the diffusion coefficient was, the more remarkable the influence was.

\subsection{Finite element modelling}

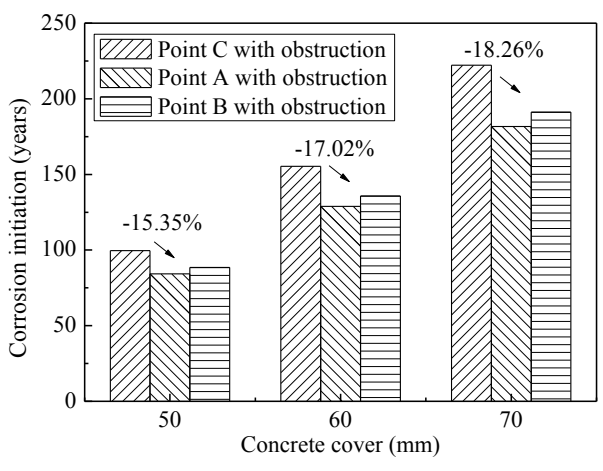

(b) $\mathrm{C} 60$

From the above analysis, the corrosion initiation time of reinforcing steel at corner of square cross-section was significantly shorter regardless of thickness of concrete cover, concrete strength and external environmental condition. In fact, bar shaped component such as column was usually influenced by chlorides from two directions and form shaped component such as wall was usually influenced by chlorides from one direction. However, specific requirements on this problem had not been put forward by industry standard in China. 


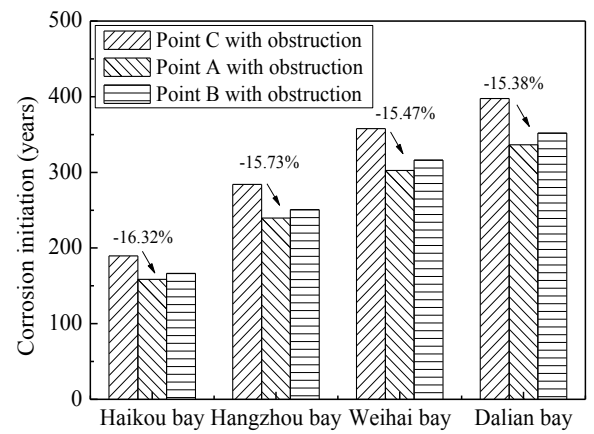

(a) $\mathrm{C} 50$

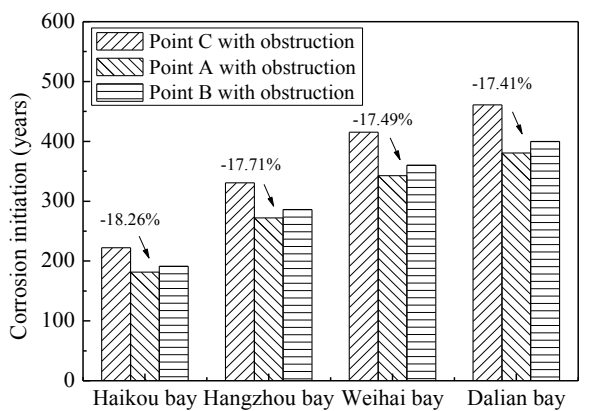

(b) $\mathrm{C} 60$

Figure.3 Corrosion initiation time at point A and B for different bays

\section{Durability service life calculated by Monte Carlo method}

The corrosion of reinforcing steel induced by chloride was a slow and complex process, which involved many material and environmental variables. The durability service life of RC structure assessed by deterministic method didn't conform to the real case and probabilistic limit state method.As corrosion propagated very quickly after initiation, in this paper, corrosion initiation was taken as durability limit state which the structure was able to meet its specified durability requirements with an acceptable level of safety. When the failure probability of the RC structure exceeded acceptable failure probability, durability service life of RC structure was finished.

\subsection{Statistical description of influencing parameter}

1) Concrete cover $c$

Randomness of thickness of concrete cover need to be considered due to the construction deviation. At present, most of the researches at home and abroad showed that the thickness of concrete cover obeyed normal distribution. Table 1 showed a summarization of statistical description of thickness of concrete cover. In this paper, truncated normal distribution (least bound was $10 \mathrm{~mm}$ ) with coefficient of variation (COV) 0.2 was taken.

Table 1 Statistical description of concrete cover

\begin{tabular}{|l|l|l|}
\hline Researcher & COV & Probability distribution \\
\hline Vu and Stewart & 0.25 & truncated normal distribution (least bound was 15mm) \\
\hline Kirkpatrick et al & 0.10 & normal distribution \\
\hline Val and Trapper & 0.25 & truncated normal distribution (least bound was 10mm) \\
\hline Muigai et al & 0.20 & truncated normal distribution (least bound was 0mm) \\
\hline Duan et al & 0.20 & normal distribution \\
\hline Moradian et al & 0.24 & normal distribution \\
\hline
\end{tabular}

2) Surface chloride ion concentration $C s$

Randomness of surface chloride ion concentration need to be considered due to rainfall, wind direction and force. Table 2 showed a summarization of statistical description of surface chloride ion concentration. In this paper, lognormal distribution was taken. For atmospheric zone and splash and tidal zone, the influence of the external environment was obvious. In consideration of different environment conditions, COV were respectively taken as 0.3 and 0.1 . For submerged zone, the environment condition was stable, COV was taken as 0.1 . Mean value of surface chloride ion concentration were respectively taken as $39.6 \mathrm{~kg} / \mathrm{m} 3,88.75 \mathrm{~kg} / \mathrm{m} 3$ and $123.36 \mathrm{~kg} / \mathrm{m}^{3}$ for atmospheric zone, splash and tidal zone and submerged zone.

Table 2 Statistical description of surface chloride ion concentration

\begin{tabular}{|l|l|l|}
\hline Researcher & COV & Probability distribution \\
\hline Marques et al & 0.10 & normal distribution \\
\hline Val & 0.30 & normal distribution \\
\hline Val andTrapper & 0.20 & normal distribution \\
\hline
\end{tabular}




\begin{tabular}{|l|l|l|}
\hline Vu and Stewart & 0.50 & lognormal distribution \\
\hline Duan et al & 0.30 & lognormal distribution \\
\hline Moradian et al & 0.16 & normal distribution \\
\hline Kwon et al & 0.08 & normal distribution \\
\hline Muigai & 0.21 & gamma distribution \\
\hline
\end{tabular}

3) Initial diffusion coefficient $D_{0}$

Randomness of initial diffusion coefficient need to be considered due to deviation of material, match ratio, agitation, pour and curing. Table 3 showed a summarization of statistical description of initial diffusion coefficient. Lognormal distribution with COV 0.2 was taken.

Table 3 Statistical description of initial diffusion coefficient

\begin{tabular}{|c|c|c|}
\hline Researcher & COV & Probability distribution \\
\hline Duan et al & 0.20 & lognormal distribution \\
\hline Val and Trapper & 0.20 & lognormal distribution \\
\hline Kwon et al & 0.13 & lognormal distribution \\
\hline Marques et al & 0.20 & normal distribution \\
\hline
\end{tabular}

4) Critical concentration $C_{\mathrm{r}}$

For atmospheric zone and splash and tidal zone that oxygen can easily reach the surface of the steel, uniform distribution with range $0.1 \%-0.25 \%$ (free chlorine ion as a percentage of weight of binder) was taken as critical content.

\subsection{Kriging modeling}

Monte Carlo method which was a statistic repeated sampling method was used to determine the corrosion initiation time distribution. The minimum sampling times was usually determined by the following equation:

$$
N \geq 100 / P_{\mathrm{f}}
$$

Where $\mathrm{N}$ was minimum sampling times, $P_{\mathrm{f}}$ was the acceptable failure probability. In this paper, acceptable failure probability was taken as $10 \%$, therefore minimum sampling times $\mathrm{N}=1000$.

If each sample were calculated by finite element model, it would consume huge time. In this paper, Kriging model was used to estimate corrosion initiation time which can be set up with a small size train sample.Central composite design (CCD) method was used to establish the train sample. According to central composite design, 5 levels $( \pm 1$, $\pm \alpha$ and 0 ) should be selected for each variable, which shown in Figure 4, where $\mathrm{x}$ and $\mathrm{y}$ axes respectively represented a variable. It contained 3 parts: factorial design ( $2 \mathrm{n}$ points at corner), a center point and $2 \mathrm{n}$ axial points, where $\mathrm{n}$ was the number of variables. So size of train sample was 25 for 4 variables.

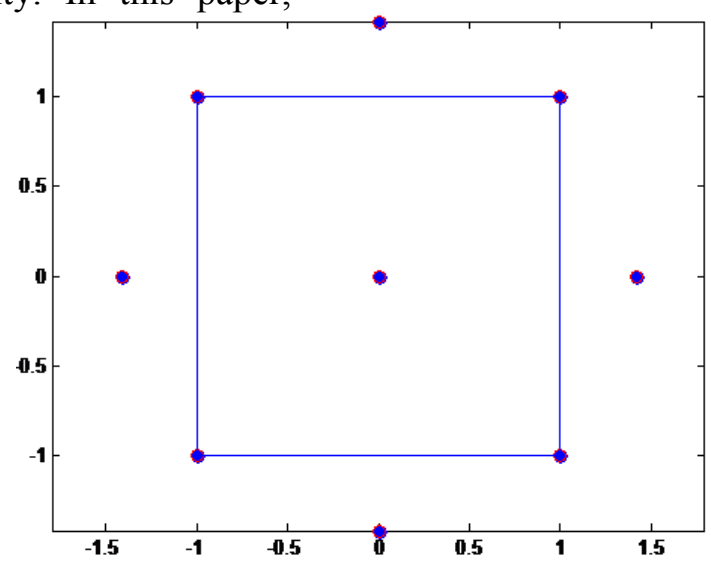

Figure. 4 Central composite design for two variables schematic diagram

There were three characteristics of Kriging model: 1) if the input point was one of the train sample points, the estimation was entirely accurate; 2) the nearer from the train sample points the input point was, the more accurate the estimation was; 3 ) if the input point was outside the scope of train sample points, it would produce larger deviation. 


\subsection{Precision testing}

An example was used to verify the prediction precision of Kriging model in the whole space experiment. A C50 RC structure exposure to tidal/ splash zone located at Haikou bay was simulated. The mean of thickness of concrete cover was $50 \mathrm{~mm}$. With the distributions of $C_{s}, C_{r}, D_{0}$, and $c$, train sample was established. Kriging model was constructed based on the toolbox "DACE" of MATLAB software. Corrosion initiation time calculated by finite element model called real value, and corrosion initiation time predicted by Kriging model called estimated value. As shown in Table 4, the estimated value and the real value to matched pretty well.

Table 4 The error of Kriging model

\begin{tabular}{|l|c|c|c|c|c|}
\hline The error & $\begin{array}{c}\text { Mean absolute } \\
\text { error }\end{array}$ & $\begin{array}{c}\text { Maximum } \\
\text { absolute error }\end{array}$ & $\begin{array}{c}\text { Mean } \\
\text { relative error }\end{array}$ & $\begin{array}{c}\text { Maximum } \\
\text { relative error }\end{array}$ & $\begin{array}{c}\text { Mean square } \\
\text { error }\end{array}$ \\
\hline Point B & 1.07 years & 4.49 years & $1.24 \%$ & $3.65 \%$ & 1.50 years \\
\hline Point A & 1.14 years & 5.33 years & $1.43 \%$ & $3.11 \%$ & 1.66 years \\
\hline
\end{tabular}

\section{Conclusion}

In this paper,. The influences of the variability on boundary chloride concentration, thickness of concrete cover, and chloride diffusion coefficient on cumulative distribution of corrosion initiation of reinforcing steel were studied thoroughly.

(1) The corrosion initiation time for reinforcing steel placed in corner of square cross-section was lesser because of 2-D diffusion, especially for thicker concrete cover, higher concrete strength, and higher diffusion coefficient.

(2) The influence of COV of surface chloride ion concentration on durability service life was not obvious. Increasing thickness of concrete cover and concrete strength would significantly improve the durability service life.

(3) For different external environment and exposed zone, the durability service lives were largely different. The higher the ambient temperature, the worse the durability of the structure.

\section{Acknowledgments}

The authors would like to acknowledge the financial support from the China Postdoctoral Science Foundation (Grant NO. 71001015201705) and the Beijing Postdoctoral Science Foundation (Grant NO. Q6001015201702).

\section{References}

1. H.L.Zhao, Y.G.Zhao, Z.W.Yu, F.X.Ding. Probabilwastic evaluation of initiation time in RC bridge beams with load-induced cracks exposed to de-icing salts. Cement and Concrete Research [J]. 2011,41:365-372

2. 2007 C. Standard for durability assessment of concrete structures [S].

3. $2011 \mathrm{~J}$ T S. Specifications for Concrete Construction of Port and Waterway Engineering [S].
4. 2000 J T J. Corrosion Prevention Technical Specifications for Concrete Structures of Marine Harbour Engineering [S]. , 2001.

5. Richardson M G. Fundamentals of durable concrete, modern concrete technology[J]. 2002.

6. M.G. Stewart., K.A.T. Vu. Structural reliability of concrete bridges including of improved Chlorideinduced corrosion models. Structural Safety, 2000, 22: $313-333$

7. Trevor J. Kirkpatrick, Richard E. Weyers, Chrwastine M. Anderson-Cooka, Michael M. Sprinkel. Probabilwastic model for the chlorideinduced corrosion service life of bridge decks. Cement and Concrete Research 2002,32, 1943-1960

8. Dimitri V. Val, Pavel A. Trapper. Probabilwastic evaluation of initiation time of chloride-induced corrosion. Reliability Engineering and System Safety [J]. 2008, 93:364-372.

9. Muigai R, Moyo P, Alexander M. Durability design of reinforced concrete structures: a comparwason of the use of durability indexes in the deemed-tosatwasfy approach and the full-probabilwastic approach [J]. Materials and structures, 2012, 45(8): 1233-1244.

10. A.Duan, J.G.Dai, W.L.Jin. Probabilwastic Approach for Durability Design of Concrete Structures in Marine Environments. Materials in Civil Engineering[J]. 2014.

11. M.Moradian , M. Chini, M. Shekarchi. Durability Performance of a Structure Made with HighPerformance Concrete and Prefabricated Elements in a Marine Environment. Performance of Constructed Facilities[J]. 2014.

12. Zhao Shangehuan. Study on Zoning of Marine Environment Based on Concrete Structure Durability [J]. Journal of Highway and Transportation Research and Development, 2010, 27(7): 61-64. 